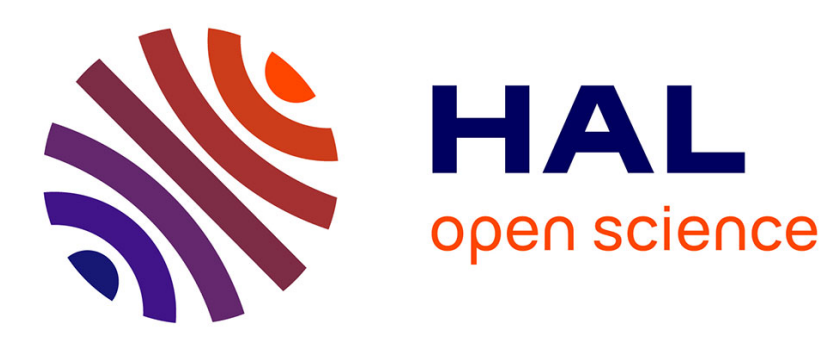

\title{
Broadening, shift and depolarization of the second resonance doublet of potassium perturbed by rare gases \\ E. Roueff
}

\section{To cite this version:}

E. Roueff. Broadening, shift and depolarization of the second resonance doublet of potassium perturbed by rare gases. Journal de Physique Lettres, 1977, 38 (15), pp.307-310. 10.1051/jphyslet:019770038015030700 . jpa-00231383

\section{HAL Id: jpa-00231383 https://hal.science/jpa-00231383}

Submitted on 1 Jan 1977

HAL is a multi-disciplinary open access archive for the deposit and dissemination of scientific research documents, whether they are published or not. The documents may come from teaching and research institutions in France or abroad, or from public or private research centers.
L'archive ouverte pluridisciplinaire HAL, est destinée au dépôt et à la diffusion de documents scientifiques de niveau recherche, publiés ou non, émanant des établissements d'enseignement et de recherche français ou étrangers, des laboratoires publics ou privés. 


\title{
BROADENING, SHIFT AND DEPOLARIZATION OF THE SECOND RESONANCE DOUBLET OF POTASSIUM PERTURBED BY RARE GASES
}

\author{
E. ROUEFF $(*)$
}

Dept d'Astrophysique Fondamentale $\left({ }^{* *}\right)$

Observatoire de Meudon, 92190 Meudon, France

(Reçu le 12 mai 1977, accepté le 22 juin 1977)

\begin{abstract}
Résumé. - On calcule les constantes de dépolarisation, d'élargissement et de déplacement de la raie de résonance du potassium $5{ }^{2} \mathrm{P} \rightarrow 4{ }^{2} \mathrm{~S}$ perturbée par tous les gaz rares dans un traitement couplé tenant compte des effets de rotation et de structure fine dans le cadre de l'approximation semiclassique pour $T=450 \mathrm{~K}$. On a utilisé les potentiels de Pascale et Vandeplanque [1] et supposé une trajectoire rectiligne. Les résultats sont discutés. Les comportements inhabituels devraient disparaître dans un traitement quantique et des tests expérimentaux supplémentaires seraient les bienvenus.
\end{abstract}

\begin{abstract}
The depolarization, broadening and shift constants of the $\mathrm{K} 5{ }^{2} \mathrm{P} \rightarrow 4^{2} \mathrm{~S}$ resonance line perturbed by rare gases are calculated in a coupled treatment taking into account rotational and fine structure effects in the frame of the semi-classical approximation for $T=450 \mathrm{~K}$. Pascale and Vandeplanque [1] interatomic potentials are used and a rectilinear trajectory is assumed in the calculations. Results are discussed. Some unusual features should be removed in a quantal treatment and further experimental tests would be welcome
\end{abstract}

1. Introduction. - Collisions with perturbing atoms have two effects on spectral lines. On the one hand, they produce a change in the spectral line profile leading to additional width and shift, and on the other, they change their polarization state which is partially destroyed during the collision. Now that systematic calculations of the interatomic molecular potentials (Pascale and Vandeplanque [1]) are available, for alkali-rare gas pairs, we have been led to perform the corresponding computations on the $\mathrm{K} 4 \mathrm{~s}-5 \mathrm{p}$ line. We have previously used the asymptotic exchange model to compare experimental and theoretical results for the case where helium is the perturber (Kunth et al. [2]).

2. Broadening, shift and relaxation constants. In the case of the $\mathrm{K}\left(5^{2} \mathrm{P}-4{ }^{2} \mathrm{~S}\right)$ transition, the fine structure splitting of the $5 p$ resonance level is small $(18.75 \mathrm{~cm})$ so that the two fine structure states have to be considered together and the basis set for the excited state consists of the six corresponding Zeeman substates. The calculations are performed for a mean

\section{Also :}

(*) Laboratoire de Physique, ENSJF, 1, rue Maurice-Arnoux, 92120 Montrouge, France.

(**) G.R. 24 du C.N.R.S. relative velocity corresponding to $450 \mathrm{~K}$ which is a common laboratory situation. The procedure for the calculation of the $S$ matrix is exactly the same as the one reported in Deleage et al.'s paper [3] which takes into account the fine structure coupling as well as the non-adiabatic part of the hamiltonian in the semiclassical method reported here using a rectilinear trajectory.

The calculations which follow make use of the data of the $V_{\Sigma}$ and $V_{\Pi}$ potentials given by Pascale and Vandeplanque [1] for all potassium-rare gas pairs. Knowing the different $S$ matrix elements in a fixed frame we obtain :

i) The broadening $w$ and shift $d$ constants by the application of the formula given in Tsao and Curnutte [4] to the alkali-rare gas collisions

$$
(w+i d)_{i}=2 \pi N \bar{v} \int_{0}^{\infty} \rho \Pi_{i}(\rho) \mathrm{d} \rho
$$

with

$$
\Pi_{i}(\rho)=1-\frac{S_{f f}^{-1}}{2 j_{i}+1} \operatorname{Tr}\left(S_{i}\right)
$$

using the usual notations. Subscript $i(f)$ refers to the $j_{i}$ excited ( $j_{f}$ ground) state. 
ii) The different relaxation constants corresponding to collision induced depolarization phenomena. The expressions are given in many papers (see for example Omont [5]). There are two contributions to the relaxation constants $\gamma_{j}^{x}$ : one arises from population transfer to the other fine structure state $\gamma_{j}^{0}$ and the other from the transitions between the Zeeman substrates within each fine structure state $\Lambda_{j}^{x}$ :

$$
\gamma_{j}^{x}=\gamma_{j}^{0}+\Lambda_{j}^{x}
$$

$\gamma_{j}^{0}$ is in fact the fine structure transition cross-section whereas for $x \neq 0, \gamma_{j}^{x}$ refers to the multipolar components of the density matrix $(x=1$ orientation; $x=2$ alignment ; $x=3$ octupolar moment). We have expressed the different $\Lambda_{j}^{x}$ as functions of the individual $S$ matrix elements (see Masnou and Roueff [6]) rather than of the irreductible components of the $S$ matrix [5].

In the impact parameter approximation, we have :

$$
\Lambda_{j}^{x}=2 \pi \int_{0}^{\infty} \rho \mathrm{d} \rho P_{j}^{x}(\rho)
$$

with

$$
P_{j}^{x}(\rho)=1-\sum_{\substack{r r^{\prime} \\
s s^{\prime}}}(-)^{r-s}\left(\begin{array}{ccc}
j & j & x \\
r & -r^{\prime} & r^{\prime}-r
\end{array}\right)\left(\begin{array}{ccc}
j & j & x \\
s & -s^{\prime} & s^{\prime}-s
\end{array}\right) S_{r s}^{j} S_{r^{\prime} s^{\prime}}^{j^{\prime}}
$$

where $S_{r s}^{j}$ is the matrix element $\langle j r|S| j s\rangle$.

Transfer of orientation from one fine structure state to the other can also occur. In an alkali resonance state perturbed by a rare gas, the formula reduces to :

$$
\begin{aligned}
& \Lambda_{1 / 2 \rightarrow 3 / 2}^{1}=2 \pi \int_{0}^{\infty} \rho \mathrm{d} \rho P_{1 / 2 \rightarrow 3 / 2}^{1}(\rho) \\
& P_{1 / 2 \rightarrow 3 / 2}^{1}(\rho)=-\frac{1}{6 \sqrt{10}}\left\{\left|S_{1 / 2}^{3 / 2} 1 / 2\right|^{2}+\left|S_{1 / 2-1 / 2}^{3 / 2-1 / 2}\right|^{2}+8 \operatorname{Re} S_{1 / 2}^{3 / 2} \frac{1 / 2}{1 / 2} S_{1 / 2}^{*}{ }^{3 / 2-1 / 2}\right\}+ \\
& +\frac{1}{2 \sqrt{10}}\left\{\left|S_{1 / 2}^{3 / 2-1 / 2}\right|^{2}+\left|S_{1 / 2}^{3 / 2}-1 / 2\right|^{2}\right\}
\end{aligned}
$$

where

$$
S_{j s}^{j^{\prime} r}=\left\langle j^{\prime} r|S| j s\right\rangle \text {. }
$$

3. Results and discussion. - Table I gives the values of the broadening, shift and depolarization constants for the $4044 / 4047 \AA$ doublet perturbed by all the rare gases. Before discussing the results themselves, it is worthwhile to comment on some features of the interatomic potentials which are shown in figure 1. They can be divided into two groups :

The K-He and K-Ne pairs, on the one hand; have a very small Van der Waals minimum $\left(<10^{-6}\right.$ a.u. $)$ and a dominant repulsive part. The heavier rare gas-potassium potentials on the other hand show an important attractive part which reaches several $10^{-4}$ a.u.. Figure 1 also shows the fine structure energy $\omega$ of the $\mathrm{K}(5 \mathrm{p})$ doublet which crosses the $V_{\Sigma}$ potentials (whose values are almost equal to the difference $\left.V_{\Sigma}-V_{H}\right)$ at $R$-values which increase with the atomic number of the rare gas.

3.1 BROADENING AND SHIFT CONSTANTS. - The two components of the doublet exhibit different widths and shifts as already pointed out in [2] for the He case. However, whereas the $4044 \AA$ component is broadened more than the $4047 \AA$ one when $\mathrm{He}$ is the perturber, the situation is reversed for the other rare gases as already observed in the Na-heavy rare

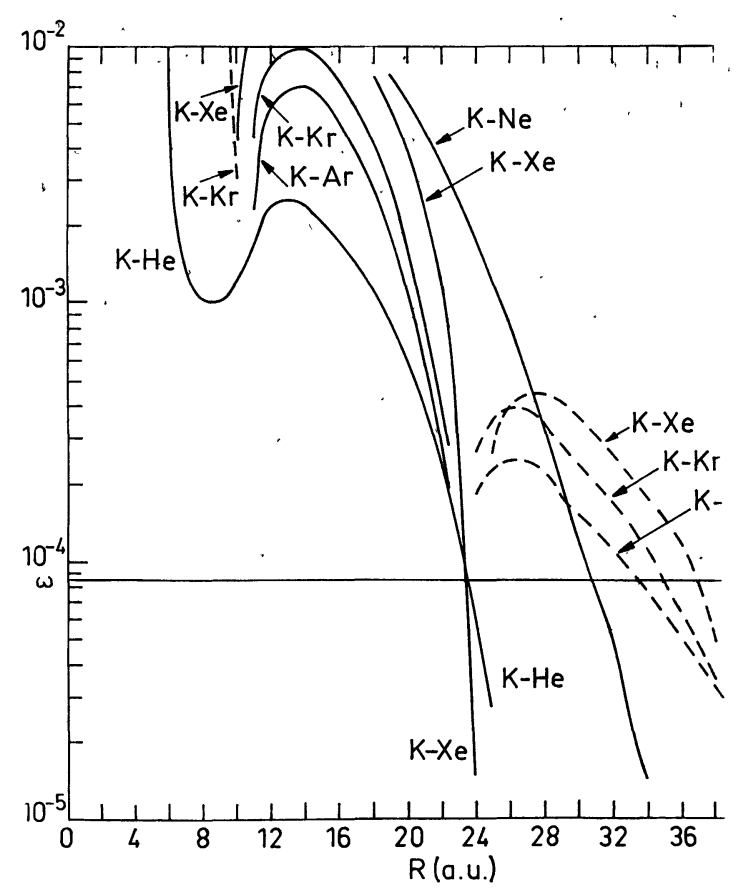

FIG. 1. - $V_{\Sigma}$ potentials relative to the excited $\mathrm{K}(5 \mathrm{p})$ state perturbed by all the rare gases in atomic units versus the internuclear distance in atomic units. Dashed lines refer to negative values of the potentials. 
gas couples by Mc Cartan and Farr [7]. The results obtained with the potentials of Pascale and Vandeplanque [1] are smaller than the previous ones where the asymptotic exchange model was used [2] ; they are also smaller than existing unpublished experimental results [8]. The theoretical results of Kielkopf [9] are based on a complete elastic phase shift calculation and do not distinguish between the $4044 / 4047 \AA$ components. The comparison with present work shows a large discrepancy for the light rare gases $(\mathrm{He}, \mathrm{Ne})$ where the non-adiabatic effects are most important, whereas the agreement is reasonable for $\mathrm{Ar}, \mathrm{Kr}$ and $\mathrm{Xe}$. New measurements concerning this doublet are in progress in this laboratory [10]. Preliminary results for the broadening and shift by helium are given in table $I$ and agree reasonably well with our theoretical data. The shifts are towards the blue for $\mathrm{He}$ and $\mathrm{Ne}$, perturbers which have very repulsive potentials, and towards the red for the heavier rare gases which indicates that the attractive part of the potential is important.

3.2 DEPOLARIZATION AND RELAXATION CROSS-SECTIONS. - The cross-sections for neon shown in table [1] are rather unexpected. Whereas the fine structure excitation cross-section and polarization transfer cross-section are much too small in absolute value, the other relaxation constants are very large. Trajectory effects should reduce these results owing to the repulsive character of the potential. Note that the simple theory of Dashevskaya and Nikitin [11] does not apply because the Massey parameter $\omega R_{1} / \hbar v$, though being larger than 1 , is never large enough for adiabatic conditions to be fulfilled. Therefore, a coupled treatment is necessary. Indeed, a comparison with our results shows that the predicted dependence on $R_{1}^{2}$ ( $R_{1}$ being the abscissa of the crossing point between the potentials and the fine structure energy) is nowhere satisfied.

\section{TABLE I}

Broadening, shift and relaxation constants

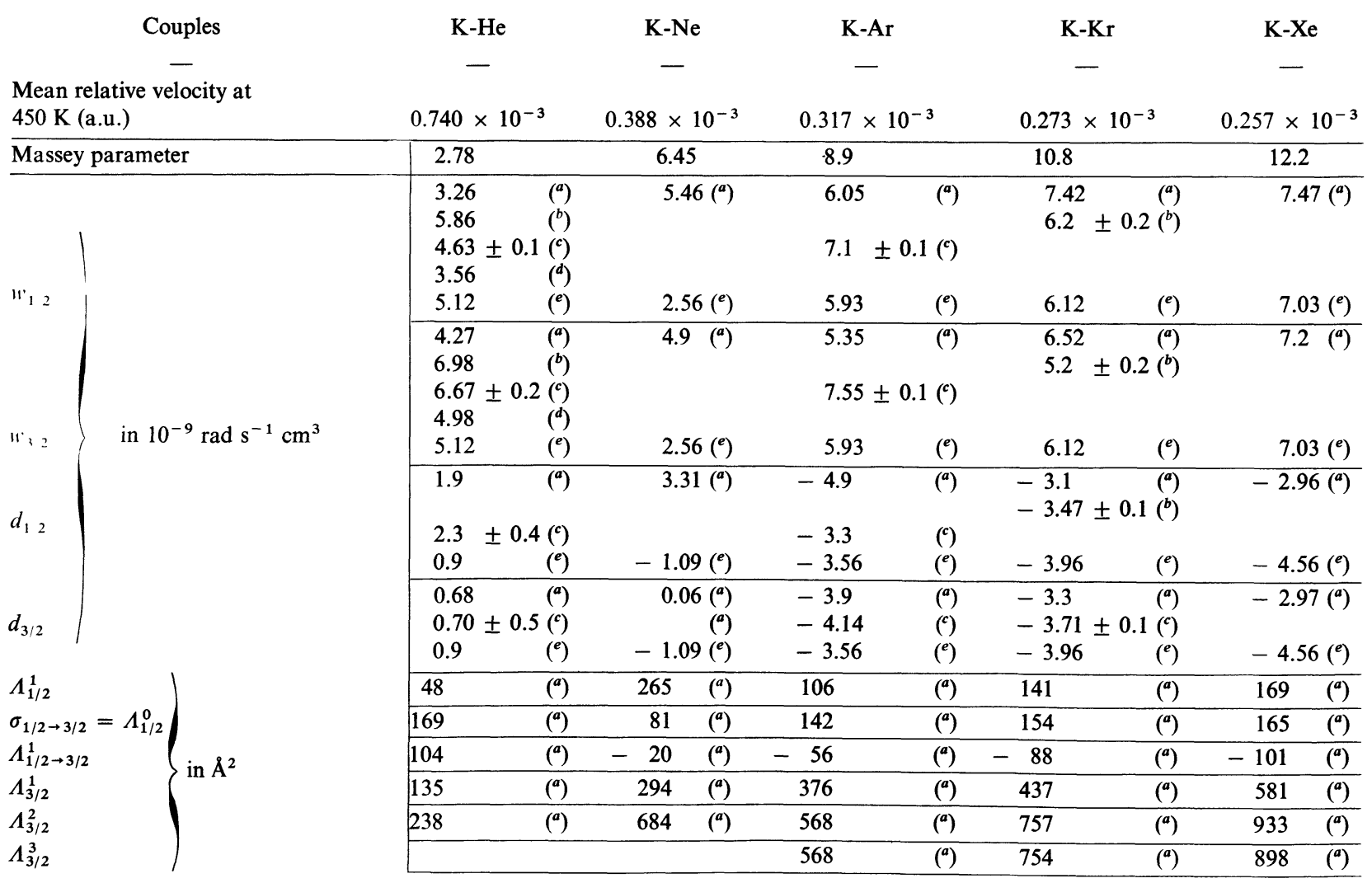

(a) Present work.

(b) Theoretical results with exchange potential [2] at $450 \mathrm{~K}$.

(c) Experimental results [8] at $475 \mathrm{~K}$.

(d) Experimental results [10] ; the relative accuracy is $10 \% ; T$ is near $450 \mathrm{~K}$.

(e) Theoretical results [9] at $500 \mathrm{~K}$. 
4. Conclusion. - Although the fine structure splitting is small and almost the same as that of the first resonance doublet of $\mathrm{Na}$, for which the physical discussion is relatively easy (see [11], [12] for example), the $\mathrm{K}(5 \mathrm{p})$ - rare gas collisions have to be calculated in a coupled treatment if we assume that the Pascale and Vandeplanque potentials are valid. A weakness of this treatment certainly lies in the assumption of a straight line trajectory which should be most critical for the depolarization relaxation constant of the $4047 \AA$ line.

However, it is not easy to take trajectory effects into account in the coupled treatment [13] and a quantal description would be more valid. We wish to emphasize, as in [2], that the size of the fine structure splitting is of fundamental importance in determining the widths and shifts of the components of the doublet. More experiments, particularly with neon as perturber, would be welcome to test the Pascale-Vandeplanque potentials [1] and the approach outlined in this letter.

Acknowledgments. - The author wishes to thank Dr. F. Rostas for critical reading of the manuscript and communication of results prior to publication. The author is also indebted to the referees for pertinent comments on this letter.

\section{References}

[1] Pascale, J. and Vandeplanque, J., J. Chem. Phys. 60 (1974) 2278.

[2] Kunth, D., Masnou-Seeuws, F., Rostas, F. and RouefF, E., J. Phys. B 8 (1975) 203.

[3] Deleage, J. P., Kunth, D., Testor, G., Rostas, F. and RouefF, E., J. Phys. B 6 (1973) 1892.

[4] Tsao, C. and Curnutte, B., J. Quant. Spectros. Radia. Transfer. 2 (1962) 41

[5] Omont, A., J. Physique 26 (1965) 26.

[6] Masnou-Seeuws, F. and RouefF, E., Chem. Phys. Lett. 16 (1972) 593.

[7] MC Cartan, D. G. and Farr, J. M., J. Phys. B 9 (1976) 985.
[8] Mc Cartan, D. G., Results reported in Progress in Quantum Electronics (1972) Vol. 2, part. III by HindMASH, W. R., FarR, J. M., SANDars, J. H. and Stenholm, S., p. 141 (Pergamon Press Ltd.).

[9] KIflKopf, J. K., J. Phys. B 9 (1976) L547.

[10] Gilbert, D., Spielfiedel, A. and Rostas, F. (1977) to be published.

[11] Dashevskaya, E. I. and Nikitin, E. E., Can. J. Phys. 54 (1976) 709.

[12] Lwin, N., Mc Cartan, D. G. and Lewis, E. L., J. Phys. B 9 (1976) L161.

[13] Gaussorgues, C. and Masnou-Seeuws, F. (1977) submitted to J. Phys. B. 